\title{
Da (re) configuração do capitalismo informacional no Haiti à economia de violência.
}

\author{
From the (re) configuration of informational capitalism in Haiti to \\ the Economy of violence.
}

\author{
Mardochée Ogécime* \\ Maria Aparecida Moura**
}

\section{RESUMO}

Trata-se de uma análise do capitalismo informacional no Haiti, na sua proposta mais emblemática em sociedade da informação e do conhecimento. Objetiva apreender a dimensão e instrumentalização das categorias "informação-conhecimento-tecnologia" como matrizes de desenvolvimento social e econômico, nas aspirações de configuração de processos (re)produtivos, organização social de trabalho e dinâmicas de desencadeamentos de processos sociais, culturais e políticos decorrentes dos ideais de bem-estar emanados das apostas da sociedade da informação e do conhecimento. Mediante uma análise documental, se estuda tanto as condições, possibilidades de (re)configuração deste modelo econômico no país como os impactos das suas procedências e aplicações na sociedade. $\mathrm{Na}$ configuração do capitalismo informacional no Haiti, se dá uma nova direção de causalidade que é estabelecida entre grupos de interesse, instituições políticas e econômicas; e a captura do Estado que resulta dela se torna o "modus operandi", com seus efeitos perversos na criação e distribuição de riqueza na economia. Estes efeitos são reprodutores de uma organização

\begin{abstract}
It is an analysis of informational capitalism in Haiti, in its most emblematic proposal in the information and knowledge society. It aims to apprehend the dimension and instrumentalization of the categories "information-knowledgetechnology" as matrices of social and economic development, in the aspirations of configuring (re) productive processes, social work organization and dynamics of the triggering of social, cultural and political processes resulting from the ideals of well-being emanating from the bets of the information and knowledge society. Through a documentary analysis, the conditions, possibilities of (re) configuration of this economic model in the country and the impacts of its origins and applications on the society are studied. In the configuration of informational capitalism in Haiti, there is a new direction of causality that is established among interest groups, political and economic institutions; and the capture of the state that results from it becomes the "modus operandi", with its perverse effects on the creation and distribution of wealth in the economy. These effects are reproductive of an economic organization torn by poverty and social inequality in the country, including the emigration of the country's
\end{abstract}

\footnotetext{
* Mestre em Ciência da Informação pela Universidade Federal da Bahia. Endereço: Av. Pres. Antônio Carlos, 6627 - Pampulha, Belo Horizonte - MG, 31270-901 Telefone: (31) 99151-0507. E-mail: danymike123@yahoo.fr

** Doutora em Comunicação e Semiótica pela Pontifícia Universidade Católica de São Paulo. Professora titular da Universidade Federal de Minas Gerais (UFMG). Endereço: Av. Pres. Antônio Carlos, 6627 Pampulha, Belo Horizonte - MG, 31270-901 Telefone: (31) 3409-5249. E-mail: cidamoura@gmail.com
} 
econômica dilacerada pela pobreza e desigualdade social no país, inclusive a emigração da força de trabalho do país.

Palavras-chave: Capitalismo Informacional; Sociedade da Informação e do Conhecimento; InformaçãoConhecimento-Tecnologia;

Desenvolvimento; Governança Territorial. workforce.

Keywords: Informational Capitalism; Information and Knowledge Society; Information-Knowledge-Technology; Development; Territorial Governance.

\section{INTRODUÇÃO}

Em dezembro de 2003, representantes de governos, entre os quais membros do governo haitiano, empresas multinacionais e atores da sociedade civil se reuniram em Genebra para a primeira Cúpula Mundial sobre a Sociedade da Informação. Durante este fórum, o locus dos debates esteve nas novas tangentes do quadro de desenvolvimento dos países, desde uma perspectiva globalizante da Economia mundial. Com a alegação de "representar os povos do mundo" (WORLD SUMMIT..., 2005), o encontro teve por objetivo o desenvolvimento da sociedade da informação, apostando-se nas possíveis mediações do desenvolvimento de tecnologias do conhecimento, informação e comunicação (TICs), para a inclusão dos países, entendidos como periféricos, em uma economia globalizada.

Para o Haiti, sendo considerado país periférico, esta abordagem pressupõe que a repartição dos frutos do crescimento alimentado pelas TICs possa contribuir à erradicação da pobreza, ao desenvolvimento sustentável, à criação de empregos de qualidade, à distribuição equitativa da riqueza no país e a uma melhor reorganização do trabalho na sua essência internacionalizada; além do equilíbrio tecnológico com o 'outro' desenvolvido, desde a apreensão de um arranjo econômico organizado pelas matrizes informação-conhecimento-tecnologia (WORLD SUMMIT..., 2005).

Deste ponto de vista, a sociedade da informação e do conhecimento torna-se natural e necessária ao país (GOUVERNEMENT..., 2012). Esta nova sociedade passa a ser justificada pela suposta capacidade de melhorar as condições materiais e sociais de existência da população. A articulação da fé torna-se mais uma questão amplamente aceita, sugerindo que o simples fato de existirem informações disponíveis faria as pessoas acessarem e usufruírem delas, criando atividades capazes de fazê-las viver melhor e de forma plena. Cogita-se ainda que, através da disponibilização de informações e da aquisição de tecnologias de informação e conhecimento, demandas diretas por aumento da igualdade social e distribuição de renda seriam alcançadas (OGÉCIME; MOURA, 2019b).

Entretanto, a análise do contexto histórico e das iniciativas decorrentes deste modelo econômico reforça as suspeições de que a economia da informação seja apenas um bom álibi para as instituições internacionais, o governo e os agentes econômicos quanto à situação de subdesenvolvimento do Haiti; isto é, deslocar a centralidade das causas reais do problema, as transferindo nos desdobramentos externos invocando as categorias: a informação, o conhecimento e as tecnologias.

Desse modo, este artigo busca recuperar, à luz da crítica imanente, as propostas e aspirações do capitalismo informacional na sua expressão emblemática e social mais recente em forma de sociedade da informação e do conhecimento no país. As categorias "informação-conhecimento-tecnologia" seriam os condicionantes principais da organização social e do desenvolvimento. Portanto, realiza-se a análise 
dessas propostas e aspirações a partir da filosofia política que orienta os modelos desta ideologia geral no Haiti, confrontada com os problemas decorrentes da economia industrial e a crise do "Estado-providência".

\section{ECONOMIA DA INFORMAÇÃO E DO CONHECIMENTO: UM FATOR DETERMINANTE DO DESENVOLVIMENTO NO HAITI?}

Considerar o pressuposto de que, tanto no Haiti como na esfera global, a convergência das tecnologias da informação e da informática seja um fenômeno crescente não nos conduz, necessariamente, à identificação de valores éticos, culturais e sociais intrisnsecos; e nem mesmo de um acesso equitativo à informação (seus atributos e propriedades) para todos. Ao contrário, observa-se um novo modelo de organização socioeconômica que tende a possibilitar novas condições ao capitalismo global, através da instrumentalização das tecnologias da informação e comunicação, para desenvolver novas formas de exploração ainda mais sofisticadas (BASSO, 2005).

Relacionada às novas mutações estruturais da economia globalizada, na sociedade da informação e do conhecimento se hipotetiza que a maior parte do Produto Interno Bruto (PIB) de um país possa ser gerada pelo setor da informação, superando assim outros setores da economia (MOORE, 2014). Tal organização social supõe que a grande parte da população economicamente ativa trabalha em atividades relacionadas com a produção, a comercialização, os serviços e sistemas de informação. Nos Estados Unidos da América, por exemplo, em 2016, entre a metade $(1 / 2)$ e dois terços (2/3) da força de trabalho esteve diretamente ou indiretamente ligada ao setor da informação (ÉCOLE..., 2020). Sob este ângulo, as telecomunicações e a informação tornaram-se um recurso vital para o bem-estar social, a segurança nacional e a competitividade do país (AGUADERO, 1997).

Ao contrário, de 2000 a 2012, produziu-se no Haiti um efeito contraste às teses de BELL (1978) e TOURAINE (1969) no que diz respeito ao fundamento de uma sociedade pós-industrial como substituto natural de uma sociedade de serviços. Durante esse período, observou-se uma diminuição do valor agregado de $22,64 \%$ a $17,73 \%$ do valor do PIB para o setor da agricultura; de 9,6\% a 6,60\% para o setor da fabricação, de $43.03 \%$ a $24.76 \%$ para o setor de serviços; e, um aumento considerável de $30.85 \%$ a $55.20 \%$ do setor da indústria (ÉCOLE..., 2020). 


\section{Evolução do valor agregado por sector}

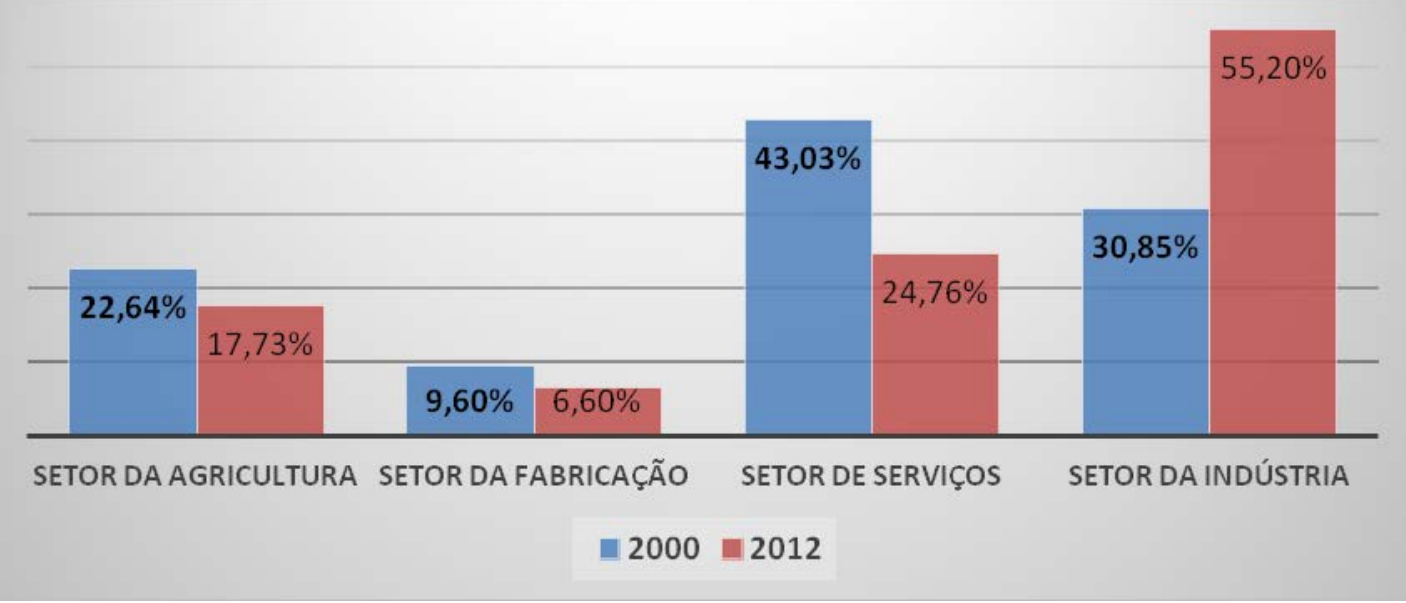

Fonte: ÉCOLE ..., 2020 (elaborado pela autoria, 2020)

No país, a hipótese da normalização de um novo capitalismo de natureza informacional pode-se instituir em um modelo de economia que se assenta na mediação complexa do desenvolvimento de novos mecanismos de exploração do valor produzido pelo trabalho, através da instrumentalização das TICs. Esta intensificação da espoliação sobre a força de trabalho, bem como o desenvolvimento sem precedentes de uma acumulação de tipo financeiro resultam-se no endividamento maciço do governo e das famílias (SANTOS, 2013; MEF, 2017).

Consequentemente, há mais de 20 anos, as despesas do governo excederam suas receitas. Esta situação pode ser explicada pelo desejo do Estado de adotar uma política orçamentária expansionista com o objetivo de estimular o crescimento econômico e a criação de empregos desde a perspectiva das novas mutações estruturais do projeto capitalista globalizado (MINISTÈRE..., 2017). Para preencher a lacuna entre a receita doméstica e as despesas públicas, os sucessivos governos não tiveram escolha a não ser de recorrer ao financiamento por meio de empréstimos (internos e externos), além de doações, particularmente, das agências internacionais, para aumentar a atividade econômica (RIDORÉ, 2011; LABOUSSIERE, 2013).

\section{Gráfico 2: Evolução do estoque da dívida externa em milhões de dólares}

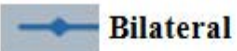

Multilateral

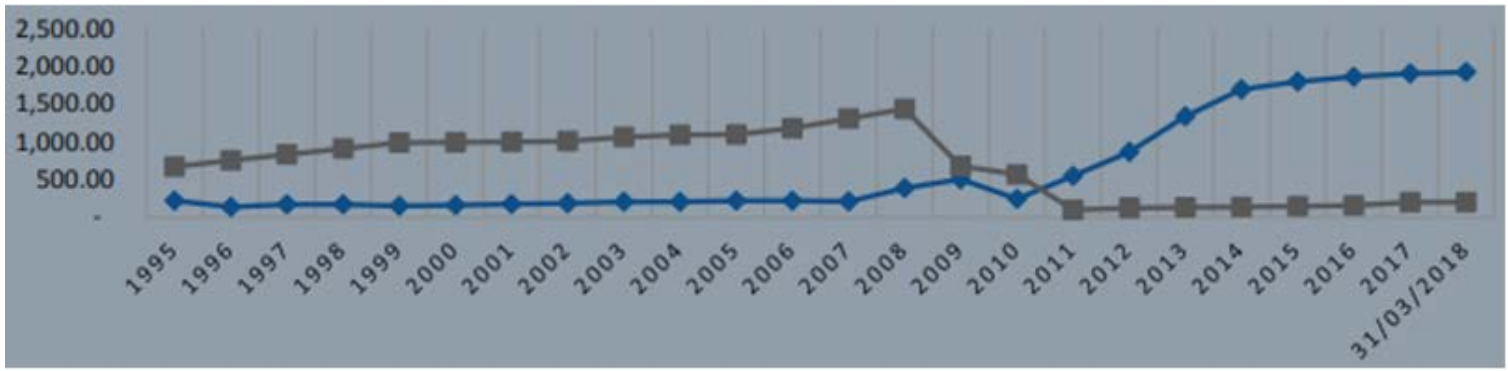

Fonte: Haiti, MEF, 2018. 
Esta política provocou um aumento substancial da dívida soberana que levou ao cancelamento da dívida do Haiti por credores internacionais (cancelamentos: PPME países pobres muito endividados e pós-terremoto). Em quase sete anos após o último cancelamento, que ocorreu em 2010, o estoque da dívida pública do Haiti atingiu o nível anterior ao processo de cancelamento (MEF, 2017). O aumento persistente do estoque da dívida externa do país, nos últimos 25 anos, é resultado das escolhas econômicas para a tentativa da normalização da economia aos moldes da terceira revolução industrial (EMILE, 2017).

Decorrente desse cenário, atrair a produção de baixa renda para este país nunca foi tão efetivo (BUREAU..., 2015). A estratégia de crescimento dos países desenvolvidos, historicamente herdada da forte presença da burguesia desde a internacionalização da primeira revolução industrial, parece se tornar, cada vez mais, o caminho ideal do empoderamento econômico baseado na eficácia da transferência da manufatura (BOST, 2007; BUZENOT, 2013). Para o Haiti, este critério se subordina tanto ao mundo das finanças como à economia real. No contexto da globalização financeira, esta concepção de transferência da violência e da política de transposição da interdependência sistêmica acarreta esta dupla dimensão: a noção do valor torna-se abstratamente dependente do seu corolário, a finança, e abrange indissociavelmente os bens com valor de mercado (OGÉCIME; MOURA, 2019b).

Isso pressupõe que o desenvolvimento de uma economia baseada na informação deva ser condicionado pela sua capacidade de produzir valor de mercado. Nessa perspectiva, os países periféricos como o Haiti se caracterizam por operar, estritamente, mudanças estruturais nas suas economias, visando a aumentar as suas quotas de mercado no comércio mundial de bens e serviços, bem como a abertura global destes mercados financeiros (PORRAS, 2015; VENTURA; BRONER, 2016).

De fato, desde 2000, tem-se observado um crescimento na economia do Haiti, recentemente aberto às nova interfaces financeiras decorrentes da transposição dos efeitos estruturais na economia do centro, no que diz respeito à exportação. De 2000 a 2018, as exportações do país aumentaram mais de 243\% (ÉCOLE..., 2020); enquanto a participação dos países desenvolvidos diminuiu de $66 \%$ para $53 \%$ no comércio mundial de 1980 a 2011. Este foi o caso dos Estados Unidos, da União Europeia e do Japão (WORLD TRADE ORGANIZATION, 2014).

Paradoxalmente, o país importou $427 \%$ de produtos de primeira necessidade durante esse mesmo período, consequência direta do déficit normativo do setor agrícola (WORLD TRADE ORGANIZATION, 2014). Diante desse cenário se pode perguntar: o que origina tal efeito paradoxal, associado de um lado ao aumento drástico na exportação do país, por outro lado, à persistência da pobreza?

Uma tentativa de resposta a essa pergunta pode ser relacionada às hipóteses que resultam dos mecanismos de penetração de mercado. Deste fundamento, entende-se que a penetração do capitalismo não é linear. As relações capitalistas de produção não substituem as relações de produção não capitalistas. A penetração do capitalismo os destrói parcialmente e os adapta. Ela é efetivada na/graças à violência (OGECIME; MOURA, 2019a). Essa violência é o veículo de penetração das relações de mercados. Tal observação pode não parecer exclusiva dos países subdesenvolvidos. Mas, é importante enfatizar que esse tipo de violência permite o desenvolvimento e a intensificação de mecanismos e instrumentos de acumulação desregularizada de lucros nos países subdesenvolvidos.

Nos países subdesenvolvidos, a violência extrai a sua especificidade da penetração brutal e massiva das relações de mercado. Esta penetração é impulsionada e 
reforçada a partir do exterior (OGECIME; MOURA, 2019a). Esse exterior é a economia do centro no início da sua especialização internacional. No Haiti, ela é constituída pela transposição econômica, inserção dessas economias na economia mundial e pela política do Estado subordinada aos interesses do mercado - devido à desvalorização das economias locais/nacionais, à sofisticada ressocialização da força de trabalho e à extinção das antigas economias (COLLIER et al., 2002). Nesse estágio, as leis de mercado parecem soberanas e, portanto, sobrepujariam qualquer alternativa que não estivessem a elas vinculadas.

Em termos estruturais, as leis deste mercado, nos seus estágios de internacionalização, trans-posicionaram a economia do Haiti cujo setor agrícola representava, no século 19, cerca de $95 \%$ na sustentação econômica do país para apenas $23 \%$ do PIB em 2009, em prol do setor de serviço que é dominado, à sua vez, pelos pequenos negócios. Este efeito é produtor da "heterogeneidade estrutural" que caracteriza a economia do país. No entanto, o setor de serviço passou de menos de $5 \%$ a $60 \%$ do valor do PIB, no mesmo período (PAUL; DAMEUS; GARRABE, 2010). A desmaterialização da economia (GALLOUJ, 1994) do país para as atividades econômicas do setor de serviço (com complexa apreensão de valores de mercados: instituições financeiras, transportes e comunicação, serviços domésticos e empresariais) resultou, no interior do país, em uma (re)mecanização do capitalismo dilacerada pela relação centro-periferia cuja atividade econômica do centro é reprodutora de cidades predatórias.

\section{OS CONTORNOS DO CAPITALISMO INFORMACIONAL E A INSTITUCIONALIZAÇÃO DA ECONOMIA DE VIOLÊNCIA}

Do quadro referencial anterior, é entendido que a lógica da concorrência internacional na sua determinação em forma do incentivo: à competitividade, a necessidade de uma configuração constante da centralidade do Estado subordinado às leis soberanas do mercado global e as suas agências, vêm acelerando o ritmo das cadências sobre os mecanismos de transferência de tecnologia, tornando-se variáveis de otimização dos processos de produção. Os países tanto subdesenvolvidos como em desenvolvimento, chamados de periféricos em outras instâncias, orientam não apenas processos técnicos (máquinas, modos de operação, know-how), mas também, adquirem uma organização social de trabalho e relações sociais específicas dos países capitalistas industrializados.

Nesta esfera, a intensificação da precarização das condições e possibilidades de desenvolvimento na periferia, a inserção excessiva e constante dos processos sofisticados de produção nas chamadas "fábricas inteligentes", (VASCONCELLOS, 2016) para maximizar o lucro, podem aprofundar ainda mais as discrepâncias entre o Haiti e esses países industrialmente desenvolvidos. Este resultado, junto à desvalorização e à extinção, em alguns casos, das economias regionais/locais, pode acelerar ainda mais os fluxos migratórios de haitianos aos países centrais e impactar as condições de vida dos menos afortunados (OGECIME; MOURA, 2019a).

Essas decorrências econômicas são reprodutoras de formas de tensões locais persistentes que impactam a inteligência coletiva e econômica, e se materializam em: instabilidade política, violência econômica na vida nacional e dependência do capital externo. Se na esfera global, a globalização financeira produz certa deslocação, reconfiguração e substituição gradual das relações de poderes na institucionalização do aparato do Estado em um espectro globalizante; na periferia, a questão da busca de outros segmentos de readaptação da autoridade do Estado produz, a sua vez, 
certa violência perpetrada pelos diversos atores que buscam a tomada do controle do aparato do Estado no seu espectro nacional.

No Haiti, as tangências das correlações destes poderes, resultaram em um modelo de economia chamada por Jean (2018) de "Economia de violência". Conforme o autor, isto se deriva à perda do poder do Estado, no seu espectro nacional. Para manter e configurar os monopólios nos diversos canais de investimento, o Estado precisa de força (GRAMSCI, 1968, 2008). No entanto, no país, não é o Estado, da sua autoridade nacional e da sua institucionalização formal, que detém essa força (JEAN, 2018).

Sob esse ângulo, pode-se dizer que no interior do capitalismo informacional se dá, no Haiti, uma nova direção de causalidade que é estabelecida entre grupos de interesse, instituições políticas e econômicas; e a captura do Estado que resulta dela se torna o "modus operandi", com seus efeitos perversos na criação e distribuição de riqueza na economia.

Sufocado pela violência externa e pela incapacidade de preservar os principais equilíbrios econômicos e sociais, janelas de "oportunidade" se abrem para todos os tipos de derivas antieconômicas e antissociais. A violência, em seu estágio interno, é instalada como um instrumento de apropriação de mercados, um elemento fundamental que imprime o funcionamento geral do sistema haitiano e, em parte, o bem-estar coletivo. Sua violência não surge das mudanças modernas na relação econômica com o mundo exterior, mas sobrevoa os grandes momentos históricos e os fatos econômicos mais marcantes (JEAN, 2015; ROSA, 2016).

Estes distúrbios de enfoques normativos para a alteridade econômica não são recentes, chegam ao país desde a instituição da nação no segundo estágio da internacionalização do capitalismo industrial. A dívida da independência submeteu o país a um regime de restrições financeiras que deixaram seu legado na economia (DALEMBERT, 2010). Sua forma contemporânea, em pleno capitalismo informacional, assume um caráter técnico, com aparências inofensivas, configurações morosas para melhorar liberalização dos mercados que desestabilizam produtos locais, incluindo preços agrícolas subsidiados desde seus poderosos países de origem (PLATEFORME..., 2008).

A dimensão histórica deste Estado violento se configurou com o surgimento de novos empreendedores e estruturas de controle: da década 90 até 2000, numa economia cada vez mais dominada por importações, privatizações dos bens e serviços públicos e pelo enfraquecimento do Estado nacional (PAUL; DAMEUS; GARRABE, 2010; JEAN, 2018); e, de 2000 até 2018, numa nova forma de coabitação do Estado com o setor empresarial. Como se fosse possível pular o estágio da industrialização para se entrar diretamente na era pós-industrial, onde as considerações sobre a aquisição de objetos e instrumentos ligados à plataforma tecnológica passam a ser consideradas como prova da disseminação da sociedade da informação e do conhecimento. Neste rumo à uma economia de prosperidade compartilhada, determinada pelos fluxos de importações e pelo enfraquecimento do Estado, o problema da invasão fica evidente para a experimentação de outras fases da colonização passiva do mercado haitiano (DUPUY, 2018; JEAN, 2018).

Das apostas mistificadas da sociedade da informação e do conhecimento como uma "transição econômica", desde uma perspectiva epistemológica geral, entende-se que a economia da informação e do conhecimento e a financeirização da economia estão intimamente ligadas. As aporias que se empreendem sobre a financeirização como modalidade de um novo capitalismo tendendo se tornar independente da restrição da acumulação de lucros mediada pelo trabalho abstrato, concedem o sentido às 
instituições financeiras como matrizes de criação de riqueza e emanação das decisões de repartição das receitas do Estado (OGÉCIME; MOURA, 2019b); sob a lógica de que são esses lugares de poderes que definem as relações de troca entre os diferentes operadores econômicos e os diferentes grupos sociais. Há, portanto, uma outra conversa que se impõe aos avanços tecnológicos.

Se novas plataformas tecnológicas decorrentes do processo de produção do capitalismo informacional impõem outras relações causais entre instituições, também é necessário empreender a função dessas instituições e o escopo das decisões que emanam delas. A proposta normativa da democratização da informação e do conhecimento por meio de novas tecnologias leva essas habilidades tanto aos lugares de construção de saberes e conhecimento, como aos lugares de intensificação da violência.

A partir da economia do conhecimento, estimulada pelas tecnologias da informação e comunicação, há motivos para esperar ou explorar possíveis soluções para lidar com essa economia de violência; mas, as competências para a efetivação deste propósito se encontram nas possibilidades e condições de desenvolvimento capitalista que configuram a concepção de governança local nos ideais de uma filosofia coesa de Estado nacional (OGÉCIME; MOURA, 2019a).

\section{DA ANORMALIDADE IMATERIAL DA ECONOMIA À ABERRAÇÃO INSTRUMENTO-INFORMACIONAL}

No país, ondas sucessivas de crises financeiras, principalmente no final da década de 1990 e nas últimas décadas, revelam os desequilíbrios entre estruturas de produção fracassadas e demandas incompreensíveis de uma população em crescimento exponencial (THOMAS, 1989; PAUL; DAMEUS; GARRABE, 2010; EMILE, 2017). A apreensão destas revelações se enquadra nos excessos de modos obsoletos de governança que estão fora de sintonia com estes enfraquecimentos manifestos na economia.

Desde a ótica da compreensão da dinâmica da política internacional, entende-se que apenas fatores exógenos (NATIONS UNIES, 2006; GOUVERNEMENT..., 2012; DEPARTEMENT..., 2017) garantiriam intervalos mais confortáveis. Esta tendência reflete a incapacidade da ordem instaurada há 214 anos, objetivada a renovar os mecanismos que sustentam o equilíbrio interno do sistema. As consequências destes modos de instrumentalização do capitalismo ganham formas nas mutações cíclicas de uma história econômica sem fim, que decorre da relação da economia do país com a economia mundial (HECTOR, 2006; DESPINAS, 2008).

Esses instrumentos e mecanismos são entendidos como o culminar de um modo parasita de acumulação de renda; o marco de referência de um ciclo de degradação do aparato produtivo, intercalado com alguns períodos de viabilidade. No interior do capitalismo informacional, esses modos de acumulação continuam entretendo o trauma da história econômica do país; trauma decorrente das primeiras mutações do estágio de internacionalização do capitalismo mundial na sua manifestação colonial mecanizando-se na: renda sobre a "importação-exportação", renda sobre o intercâmbio de dinheiro, etc. Estes instrumentos evoluem na coabitação, com a dominação de uma ou de outra conforme a evolução dos mecanismos de geração de lucro na economia informacional, mas nunca em exclusividade (EMILE, 2017).

Este regime de acumulação, reconfigurado pelo capitalismo de vigilância, encontra seus condicionantes nas redes financeiras de acumulação e se manifesta através do 
controle que estas redes exercem sobre o comportamento do mercado e, portanto, sobre a distribuição (RIDORÉ, 2011; ALLIANCE..., 2013). No entanto, a ordem de exclusão aparece esgotada, pois dela emana um aparato produtivo deficiente na economia global do país (DESPINAS, 2008). Em consequência, esta ordem não conseguiu estabelecer um ambiente para o surgimento de um nicho considerável de "produção de valor" com um padrão de geração de renda acima da linha da pobreza, o que sustentaria os aparentes êxitos do projeto capitalista no país.

Em termo de normalização econômica, o sistema não se preocupou em transformar os seus agricultores, em maior parte, descendentes de escravos e negros, em empreendedores reais; o que lhes permitiria assumir o controle e, eventualmente, formar uma classe "intermediária" capaz de estimular o desenvolvimento conforme as demandas concretas e reais do país (BAZIN, 2006; DESPINAS, 2008; EMILE, 2017). Além das promessas do desenvolvimento sustentável, na sua expressão mais moderna em "sociedade da informação e do conhecimento", o potencial permanece inexplorado e as crises recorrentes refletem a anormalidade deste modo de acumulação.

$\mathrm{Na}$ tentativa de normalizar a sociedade da informação e do conhecimento no país, este regime se desdobra e se consubstancia em um certo "empreendedorismo" glamourizado - herdado, de um lado, da intensificação e propagação da ideologia da propriedade privada e, de outro lado, da consolidação gradual das grandes propriedades e redes corporativas privadas que permutam as violências globais das malhas financeiras para as esferas individuais.

A demarcação de operabilidade ontológica deste "espírito de sobrevivência" é proporcionalmente tênue à exacerbação dos limites de exteriorização da realização da vida, que se substancie, cada vez mais, nessas matrizes econômicas: "informaçãoconhecimento-tecnologia”, cujas dimensões abrangem sentidos: antropológico, psicológico, social e espiritual na formação do homem haitiano.

Esta perspectiva individualista na economia do país decorre, exatamente, da filosofia central das recentes mutações do neoliberalismo; dela, as condições de realização da vida se permutam, gradualmente, da propriedade privada às margens das grandes redes de finanças e de produção de valor que se torna, cada vez, mais abstrato.

Brisson-Lamauthe $(1996 ; 2005)$ nos seus estudos sobre a economia informal nos bairros populares da cidade de Porto-príncipe buscou compreender as mediações dadas entre as redes econômicas e o sujeito da periferia na tentativa de organizar as suas vidas nas "comunidades-centro". Conforme a autora, as atividades informais, decorrentes da precarização das condições de trabalho, reluzem a incapacidade do aparato do Estado de fornecer uma estrutura legal capaz de integrar e incluir a maioria dos pobres.

Nessa dimensão, a "economia de violência" se alicerça numa cultura operacional e estrutural que obriga os mais pobres à "manufaturar a vida" (FASS, 1990) para comer, pagar aluguel, etc. Este sistema se cristaliza num Estado que toma as aparências modernas da "Democracia" cujos instrumentos são incapazes de garantir o acesso à criação de riqueza desde uma perspectiva de igualdade e equidade. Sob esse ângulo, a precariedade pode ser vista como uma ruptura, um enfraquecimento em relação a um estado de estabilidade e de segurança mais ou menos considerável. Isto é o resultado do funcionamento do capitalismo financeirizado e globalizado, que transformou a instabilidade e a crise em seu "modus operandi" nos últimos quarenta anos (PRADO, 2005a; 2005b; BASSO, 2005; BERGER, 2009). 
As discrepâncias decorrentes da globalização financeira e intensificadas pelas tecnologias da informação e comunicação ganham formas de lutas por salários, redução do horário de trabalho e oportunidades de trabalho decente para todos no país (BUREAU..., 2015; MINISTÈRE..., 2016). Estas lutas se absorvem, na maioria das vezes, na complexidade das mediações, aparentemente invisíveis do sistema que tende a solidificar cada vez mais a apreensão da violência em alienação e estranhamento.

Se na Era neoliberal, os mecanismos de controle são mais estritos pelas capacidades e condições mitigadas pela comunicação horizontal; no país, estes mecanismos alimentam as tensões devido às profundas transformações efetivadas na organização e gestão dos processos produtivos, em oposição direta aos objetivos das lutas sociais dos anos1950-1987 no país (BAZIN, 2006). A busca pela emancipação se opõe à autonomia controlada da terceirização e economia de plataforma. A cooperação social não hierárquica é subsumida e explorada através das novas formas de organização da produção. A crítica anti-burocrática é combatida pela desregulamentação do trabalho e pelas práticas neo-gerenciais. (BASSO, 2005; MÉSZÁROS, 2011).

Para mediar esta passagem com a informalidade do trabalho, estima-se que a grande maioria dos empregos no Haiti deriva da substituição gradual do setor agrícola (47\%), setor em déficit normativo desde as primeiras propostas internacionalizantes da economia industrial, ou nos setores não agrícolas informais (45,1\%) (MINISTÈRE..., 2016). O emprego nos setores público e privado formais é raro, $4,5 \%$ e $3,4 \%$, respectivamente. Mesmo que se trabalhe no setor formal, na ausência de um sistema de proteção social, a maioria das oportunidades de emprego ainda é informal. Em consequência, quase todos os empregos no Haiti (93,6\%) são classificados como informais, tornando quase impossível alcançar condições de trabalho decentes.

Com enfoque sobressalente destas discrepâncias entre os grupos sociais, em 2012, a força de trabalho do Haiti foi estimada em 8,2 milhões, equivalente a $75 \%$ da população total do país. Destes, estima-se que 56,9\% são economicamente ativos (empregados ou desempregados). As mulheres têm menos probabilidade de pertencer à força de trabalho; representando apenas cerca de 30\% dos empregos no setor privado formal, no setor público e no setor agrícola (BUREAU..., 2015). A posição desfavorecida das mulheres no mercado de trabalho é parcialmente explicada pela distribuição desigual de tarefas domésticas: as mulheres relatam gastar duas vezes mais tempo no trabalho doméstico (15,4 horas por semana) do que os homens (menos de 7 horas por semana).

A hipótese da flexibilização do tempo de trabalho que resultaria na decência do trabalho mediado pelas tecnologias da informação e do conhecimento se enquadra numa certa aporia que se justifica nas teorias da economia dos países e comunidades centrais que conseguem se permutar da economia industrial às fábricas inteligentes (VASCONCELLOS, 2016); e, que por consequência, produz a exportação da violência na periferia seja na re-industrialização com valorização remotamente miserável ou na dificuldade de normalização ou reprodução dos padrões estruturais da economia do centro na periferia.

Conforme Bureau...(2015), a maioria dos trabalhadores no Haiti relatam exercer uma atividade de trabalho remunerada, com exceção dos trabalhadores familiares que representam $13,9 \%$ da força de trabalho ativa. Os trabalhadores familiares não remunerados estão amplamente representados na agricultura rudimentar (45,7\%), seguidos pelo setor informal não agrícola (16,2\%). Existe uma grande desigualdade de 
renda entre os setores de atividade econômica: os setores agrícola e não agrícola informal, que acolhem a grande maioria dos trabalhadores haitianos e os setores público e privado.

A incapacidade de normalizar o mercado de trabalho haitiano para gerar empregos formais suficientes para sua força de trabalho converte de fato o Haiti como o país mais desigual do continente da América, com um coeficiente de Gini de 0,76 em 2012 (um aumento de $15 \%$ em comparação a 2007). Dados esses números, não é de surpreender que $59,2 \%$ de todos os trabalhadores relatam ter renda muito instável e que $32,2 \%$ de todos os domicílios se endividam para sobreviver (BUREAU..., 2015). Deste efeito da desigualdade, MINISTÈRE... (2016) estima-se que, em 2015, 1\% da população mais rica detenha o mesmo nível de riqueza que $45 \%$ da população mais pobre.

A estruturação da violência econômica, na sua expressão e operacionalização internas, reproduz o mesmo esquema da orientação geográfica da teoria geral até então evidente na globalização financeira. No país, a pobreza é mais intensa nas zonas rurais. De fato, $80 \%$ dos pobres vivem em zonas rurais, $38 \%$ dos quais vivem em extrema pobreza, em comparação com $12 \%$ nas áreas urbanas e $5 \%$ nas áreas metropolitanas.

Decorrente destes cenários, no Haiti, o atrito entre aspirações de labelização do chamado "empreendedorismo" e outras mediações, tais como: os métodos econômicos complexos de exploração do valor do trabalho e as condições reais de trabalho faz com que um número crescente de pessoas, principalmente jovens, escolha a precariedade, entendida como a criação de condições de trabalho para a autonomia e para o exercício das próprias aspirações. Os trabalhos terceirizados são frequentemente usados para fortalecer mecanismos e condições de trabalho que permitem operacionalizar atividades não remuneradas, autônomas, "criativas" ou menos valorizadas (ZANUSO, ROUBAUD, TORELLI; 2014).

\section{DA DESMATERIALIZAÇÃO DAS ECONOMIAS LOCAIS AO CULTO À IMIGRAÇÃO}

Dado os desequilíbrios econômicos registrados entre os países do centro e os da periferia, observou-se, em 2017, que aproximadamente 258 milhões de pessoas da população mundial viviam fora dos seus países de origem e cerca de metade delas vivia nos países da OCDE (Organização para a Cooperação e Desenvolvimento Econômico). Em 2017, mais de 5 milhões de pessoas migraram para os países ricos da OCDE (OGÉCIME; MOURA, 2019a). Isso representa mais de $7 \%$ em relação ao ano anterior. Este é o quarto ano consecutivo em que os países ricos registram um aumento em seus fluxos migratórios. Além disso, em 2016, mais de 4 milhões de trabalhadores estrangeiros em condição de estadia temporária chegaram nos países da OCDE para preencher a escassez de algumas habilidades específicas (OGÉCIME; MOURA, 2019a).

Desta perspectiva, o Haiti é entendido como um país de emigração significativa, com um número crescente de emigrantes: em 2015, cerca de 1,2 milhão de haitianos viviam no exterior, ou quase $11 \%$ da população (UNITED NATIONS, 2015). A quantidade total de emigrantes e o número de emigrantes em relação à população aumentaram nas últimas décadas. Em 2000, era de cerca de 650.000 ( $9,3 \%$ da população). A instabilidade política, as práticas perversas de governança, a opressão econômica e/ou desastres naturais ampliaram os fluxos de emigração. 
Gráfico 3: Quantidade de emigrantes e porcentagem da população haitiana.

\section{Quantidade de Emigrantes e Porcentagem da População haitiana}

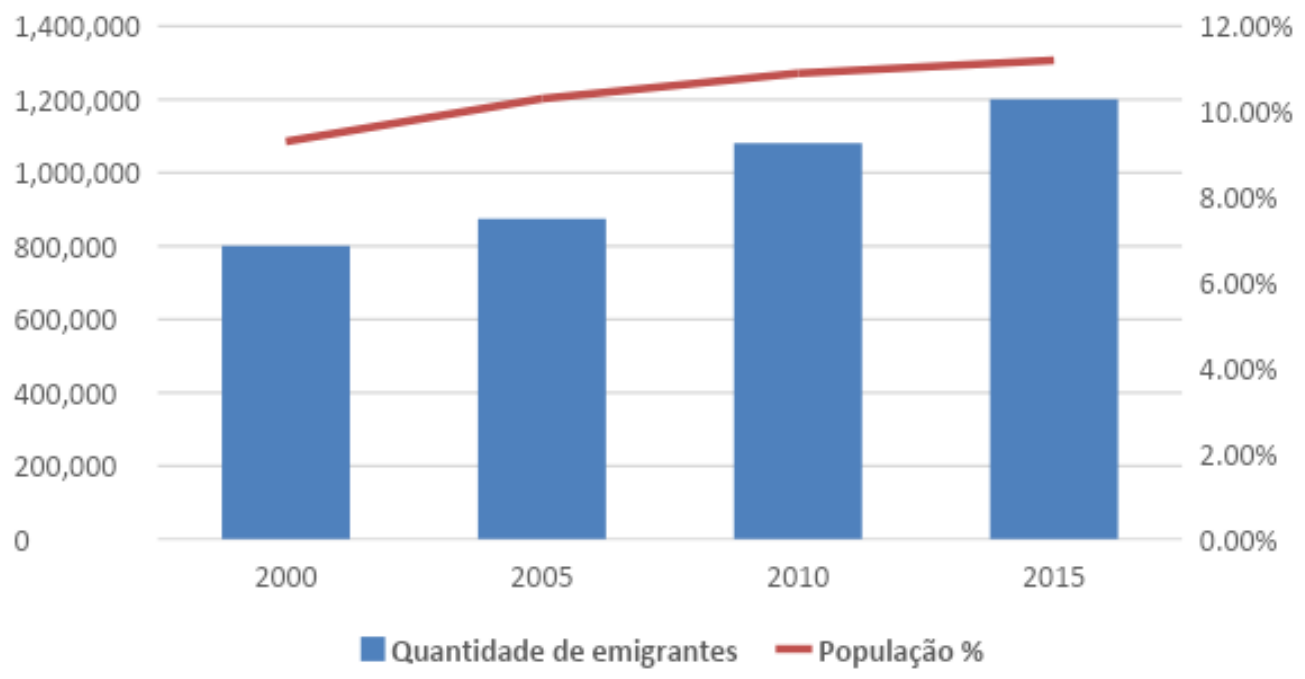

Fonte: United Nations, DAES, 2015.

Na mediação deste cenário, entre os equilíbrios econômicos dados entre os países do centro e os da periferia, observa-se um aumento, ao longo do tempo, nos fluxos de emigração dos haitianos para os países desenvolvidos (UNITED NATIONS, 2015), à exceção da República Dominicana, que conforme Larose (2016) configurou uma nova relação Norte-Sul com o Haiti. Tal relação se organizou tecnicamente nas práticas estruturais remotas deste país com a economia global. Embora, para o período pósterremoto, tenha sido registrado um aumento considerável do número de emigrantes haitianos que vivem em países em desenvolvimento, particularmente os países da América do sul. (NIETO, 2014; ORGANIZACIÓN..., 2017).

Quadro 1. Quantidade de emigrantes e porcentagem de emigrantes que vivem em países desenvolvidos.

\begin{tabular}{lllll}
\hline Ano & 2000 & 2005 & 2010 & 2015 \\
\hline Total & 792805 & 957722 & 1092025 & 1195240 \\
\hline $\begin{array}{l}\text { Países desenvolvidos } \\
\text { Países subdesenvolvidos }\end{array}$ & 505872 & 617857 & 702804 & 780962 \\
$\begin{array}{l}\text { Porcentagem de emigrantes } \\
\text { que vivem em países } \\
\text { desenvolvidos }\end{array} \quad 339865$ & 389221 & 414278 \\
\hline
\end{tabular}


Conforme dados das Nações Unidas, em 2015, os Estados Unidos são o primeiro país de destino, acolhendo cerca de 600.000 migrantes (quase metade da quantidade total de emigrantes haitianos no mundo). No entanto, outras fontes relatam um número muito maior entre 1 e 2 milhões, levando em consideração a migração ilegal (INTERNATIONAL..., 2007; BATALOVA; SCHULZ, 2017).

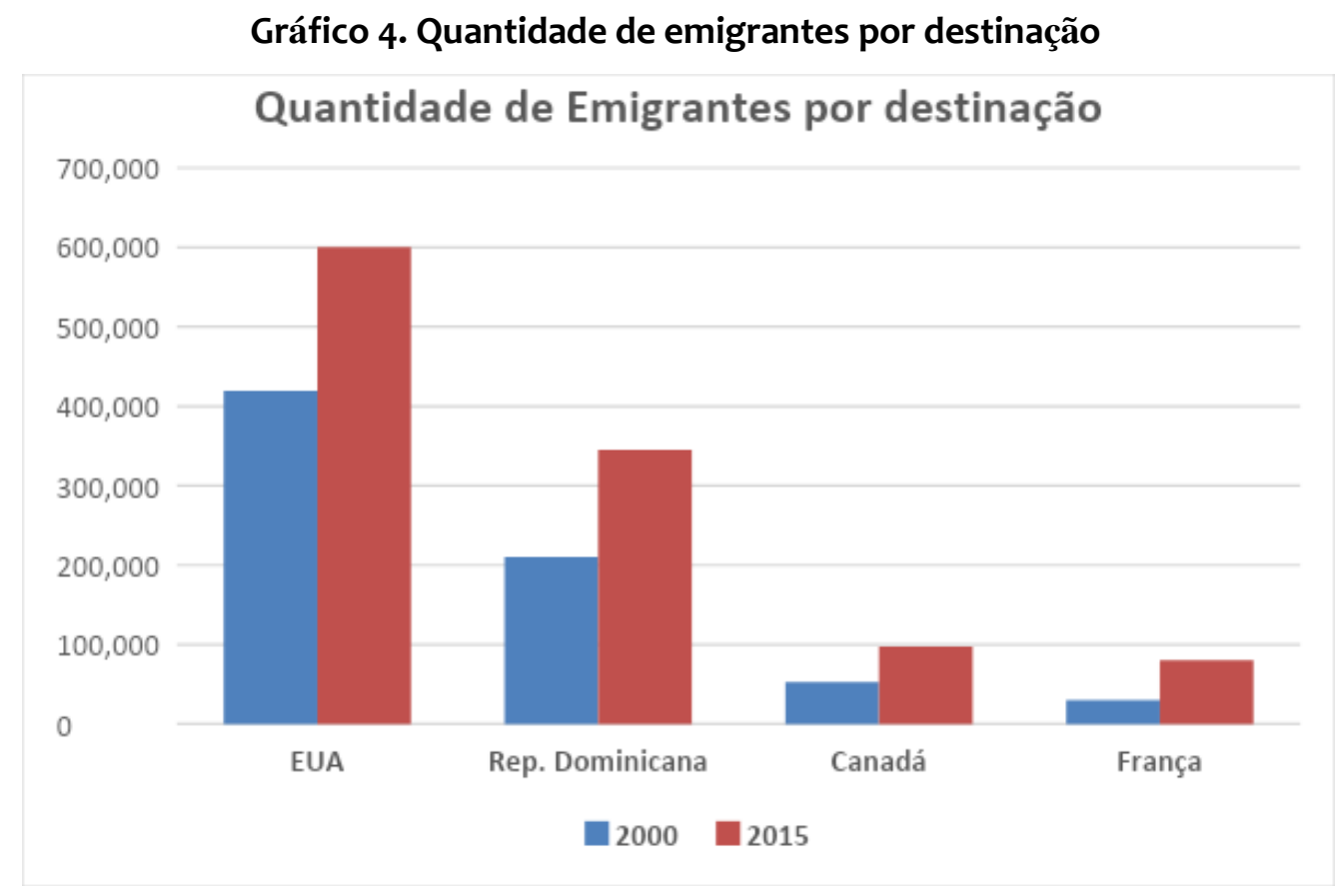

Fonte: United Nations, DAES, 2015.

Neste registro, tanto na esfera global como no Haiti, as dificuldades e estranhamentos da institucionalização e organização do capitalismo informacional, encontradas em alguns países para surfar sobre as novas mutações e entretenimentos de impactos positivistas da globalização financeira, desafiam os intelectuais, governos e agências internacionais a empreender, por meio de novas interpretações funcionalistas, essas interações entre as migrações e o desenvolvimento tanto nos trabalhos de pesquisa como nos programas nacionais de desenvolvimento.

No Haiti, esse 'modus operandi', protagonizado e intensificado pelas organizações internacionais para a compreensão do fenômeno da emigração desde uma perspectiva-utilitarista e positivista sobre a diáspora, como agências e entidades de remediação aos problemas de desenvolvimento no país, não é novo. A história mais recente desta abordagem remonta às persistentes tentativas de compensação e mensuração dos efeitos das migrações haitianas em envio de remessas, que na realidade consistem em uma categoria específica de migrantes que fogem da repressão política ou crise econômica e incapacidade do Estado de se normalizar diante as contradições complexas do projeto global de desenvolvimento. Isto se resultou, também, em uma urbanização predatória e população rural pobre desde as primeiras mutações do capitalismo na sua versão informacional. 


\section{Quadro 1. Remessas enviadas pelos emigrantes e parte dessas remessas, em porcentagem, do produto interno bruto.}

Remessas enviadas pelos migrantes $\quad-\quad-$ Parte das remessas em porcentagem do PIB

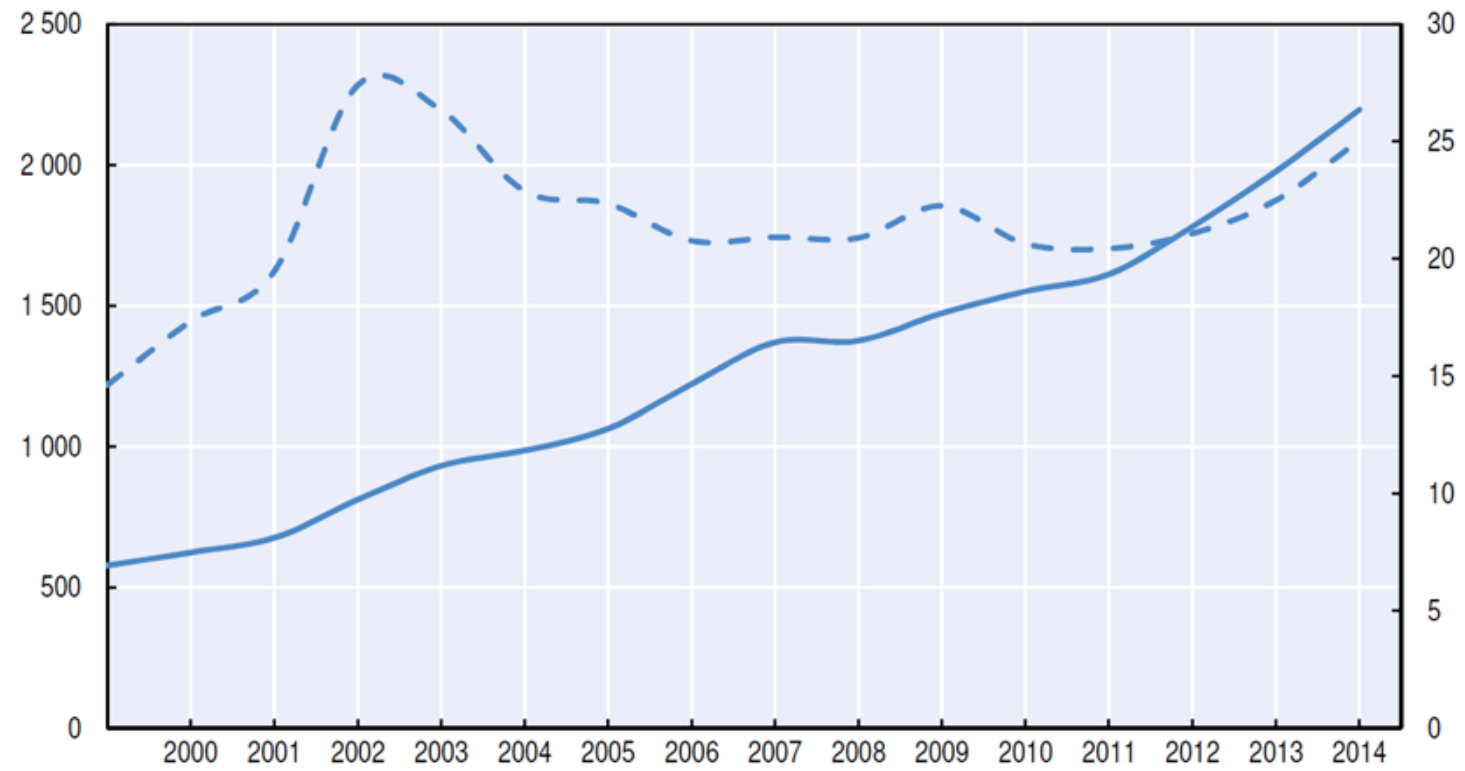

Fonte: CHARLES; ST-FLEUR, 2014.

Este fundamento funcionalista nas abordagens globais das migrações já consolidado na ideologia neoliberal, mostra claramente a minimização dos valores éticos sobre os debates das migrações, legitimando o status quo da ordem da finança mundial e suas complexas mediações ontológicas da realização de vida dos migrantes.

Isto é, desde o fundamento da economia informacional defendido por Castells (2011), o entendimento do fenômeno da migração dos países periféricos para os países do centro como uma medida paliativa de ajuste estrutural econômico pró-cíclico, capaz de contribuir para as deficiências materiais já evidentes em sociedades pobres, como o Haiti (GREENIDGE, 2015) ou em comunidades que podem ser formatadas para suas mutações. Vistos os impactos da globalização e as crescentes e contraproducentes desigualdades que ela pode causar, e que foram particularmente dolorosas no caso do Haiti (GREENIDGE, 2015), agências internacionais objetivaram programas civilizatórios de austeridade. Tais iniciativas (re)produzem as praxis de dominação da economia política que organiza a ordem internacional.

Relacionada à sociedade da informação e do conhecimento como aposta política, da qual decorrem as metas de desenvolvimento do milênio para 2000-2015 (UNITED NATIONS, 2015) e a agenda 2030 (UNITED NATIONS, 2016), uma pluralidade de perspectivas sobre o problema da migração levou a um duplo objetivo estratégico: reduzir os impactos negativos da migração e promover seus impactos e aspectos mutuamente positivos para os Estados membros e seus cidadãos, considerando os valores básicos da organização. Nesse sentido, as Nações Unidas e seus órgãos multiplicaram iniciativas em termos de produção e promoção de instrumentos de direito internacional, programas de pesquisa e ações em direitos humanos (econômicos, políticos e sociais) de migrantes, e programas de capacitação em gerenciamento da migração (INTERNATIONAL..., 2018). 
Além dos esforços envidados, os países de imigração padeceram em determinar que tipo de política pudesse ter um impacto benéfico nos países de emigração como o Haiti, promovendo as interações entre migração e desenvolvimento. Isto decorre da incapacidade de (re)descoberta de um paradigma, no interior da filosofias de desenvolvimento, uma essência de inteligência operacional capaz de superar as categorias de: concorrência, competitividade entre as comunidades e nações e exploração do outro.

Neste fundamento, ainda as relações e condições sociais e econômicas percebidas desde as configurações materiais da economia industrial aparentam produzir sentidos da razão científica para a compreensão do desenvolvimento econômico nos países periféricos além do controle dos fluxos de migração. No entanto, uma das dificuldades que enfrentam estes países é provavelmente aquela que afeta diretamente os seus cidadãos em mobilidade cujos recursos financeiros e culturais são considerados "mais limitados" e que são confrontados com importantes barreiras de emancipação econômica (DE WENDEN, 2017). Para um país como o Haiti, que deve se reconstruir após um desastre natural, essas interações cruciais exigem forte vontade política e persistência em um contexto internacional muito difícil.

$O$ entendimento do papel das migrações nas estratégias nacionais de desenvolvimento, a partir da perspectiva da governança multinível (PEREIRA, 2014), se delimita no esforço de fomentar o desenvolvimento econômico dos países de origem dos imigrantes: uma responsabilidade compartilhada, em um clima e cenário de confiança internacional, pela simples e boa razão da preponderância da filosofia da competitividade entre os estados nacionais que modelam o desenvolvimento no interior da cultura ocidental.

\section{A fuga de capital intelectual - Interações entre migrações e desenvolvimento}

Em contraste à teoria geral do capitalismo informacional, que supõe produzir conteúdos (informacionais ou culturais, em termo stricto sensu) determinantes na organização social de trabalho (LAZZARATO; NEGRI, 2001) das comunidades e países configurados como periféricos, no Haiti, a emigração se procede, em grande medida, da oferta e demanda de trabalhadores estrangeiros (LOUIDOR, 2017). A oferta é promovida principalmente pela deterioração significativa do mercado de trabalho para a juventude, como força potencial de trabalho, que muitas vezes é obrigada a escolher entre: de um lado, o desemprego desprotegido, o emprego informal, o subemprego e a precariedade; por outro lado, a emigração.

Em prol de uma economia informacional no país, que resultou em falta de oportunidades de emprego para uma juventude formada; a fuga de cérebros experimentou um crescimento exponencial recentemente.

Em 2000, entre os 419.395 haitianos identificados nos Estados Unidos da América (gráfico 4): $61,7 \%$ (de 25 anos ou mais) já haviam concluído pelo menos o ensino médio. O fator mais sobressalente e incisivo deste cenário é que $13,5 \%$ possuíam diploma universitário, mestrado ou doutorado. Portanto, só $20,4 \%$ deles tiveram a oportunidade de exercer atividades gerenciais, profissionais ou outros tipos de trabalho decente (BATALOVA; SCHULZ, 2017).

Para mediar os efeitos deste cenário, sendo elementos essenciais para a configuração e transformação do capitalismo informacional sob as lentes das condições e possibilidades de efetivação e de competitividade na globalização financeira; em 2000, apenas $1 \%$ dos haitianos que vivem no Haiti possuiam diploma universitário. Em 
2010, já havia 16,7\% dos emigrantes haitianos nos Estados Unidos da América que possuíam diploma universitário, mestrado ou doutorado (BIDEGAIN, 2012).

A demonstração da perpetuação das relações desiguais entre os polos sul-norte ou centro-periferias, se reconfigurando no interior do capitalismo informacional por meio do capital intelectual como vetor de desenvolvimento, intensificando a filosofia da competitividade entre as nações, blocos e comunidade, fica evidente no estudo de Bidegain (2012) que apontou o direcionamento incisivo da fuga de cérebros entre os emigrantes haitianos para os Estados Unidos da América e Canadá, e não para a República Dominicana.

Neste estágio, a migração internacional, entendida como um dos componentes da mundialização, continua sendo uma prerrogativa com a qual os estados preferem lidar apenas dentro do regime nacional (GAGNON, 2010). A governança da mobilidade, diferentemente das relações comerciais e financeiras é, portanto, descrita como um "não-regime" (GAGNON, 2008). Da hipótese da influência direta das mudanças estruturais de natureza econômica dos países centrais sobre os países periféricos, o quadro ético contra-exploratório aponta à necessidade de novas referências reais e concretas. Isto supõe o gerenciamento dos fluxos migratórios da mesma maneira que os fluxos comerciais ou financeiros, o que poderia incentivar os governos a adotarem uma forma de concertação interestadual e a desenvolver uma "política global" (GAGNON, 2010).

Da ideia da propagação do bem estar e mudanças estruturais efetuadas no país, que encontram as suas raízes tanto nas apostas da sociedade da informação e do conhecimento como nos efeitos da globalização financeira, é entendido que a construção de uma estrutura operacional para lidar com a migração haitiana envolve uma certa complexidade e requer a implicação de uma abordagem multidimensional de um evento social mais abrangente e dinâmico.

Conforme Kahanec (2008); Metzner (2014) e José (2015) a apreensão desta complexidade abrange duas abordagens: uma, de discriminação interseccional; e outra, da proteção complementar. A abordagem da discriminação interseccional fazse evidente nos países de destino onde a situação, causa e possibilidades de emigração se encontram em condições de vulnerabilidades; neles, os desafios são produzidos pelo acúmulo de várias condições de discriminação: por etnia e racialização cultural, idioma, situação econômica, posição social, nível de educação e status de imigração irregular, gênero, dentre outras.

Se as desigualdades que as migrações produzem são geralmente sistemática, diversas experiências mostram que as políticas públicas destinadas a combatê-la, em geral, apontam para uma ou algumas causas de discriminação e não para o efeito geral que sua acumulação produz (CLEMENS, 2014; DE WENDEN, 2017). Nesta esfera, um dos principais postulados da interseccionalidade é a disputa de qualquer forma de universalidade que considere as experiências das pessoas e das estruturas como um todo. Nesse sentido, pode-se perguntar, realmente, em qual estágio da política internacional há o enfrentamento destes efeitos desde uma abordagem geral de Direitos na prática?

A este propósito, fica evidente que, apesar da proliferação institucional nos níveis regional e internacional, a experiência dos migrantes haitianos durante o século XX e após o terremoto de 2010 mostra a natureza anárquica e inconsistente da governança global da questão da migração. Algumas dessas experiências infelizes incluem: 0 massacre de dezenas de milhares de migrantes haitianos na República Dominicana em 1937 (MADEIRA DA SILVA, 2016); a detenção extrajudicial de refugiados haitianos 
na base militar dos EUA na Baía de Guantánamo entre 1991-1993 (PAIK, 2013); a exigência de vistos de entrada por outros países membros da CARICOM em relação aos cidadãos haitianos, em violação direta às disposições de mobilidade sem impedimentos incluídos no Tratado de Chaguaramas (1973) e no Tratado Revisado de Chaguaramas (2001); a exportação extrajudicial de crianças haitianas para adoção estrangeira durante o terremoto de 2010; a apatridia de vários cidadãos dominicanos de origem haitiana em 2013 (AMNISTÍA INTERNACIONAL, 2016).

Em última instância, esses acontecimentos refletem as diversas situações de desigualdade em que se encontram grupos e comunidades haitianos historicamente discriminados e desprivilegiados em diversas partes do mundo. Eles se (re)configuram em desigualdade que, por sua vez, constrói-se historicamente racializada e dinamizada a partir do século XIX, mutando-se em noções de raça, cor disseminadas, desde a ótica de construtos ocidentais, nas regiões consideradas como periféricas. Essas noções ocidentalizadas de diferenças fundam construtos que desvalorizam identidades, grupos "não brancos" e comunidades que não encontram rumo nas suas normatizações, reproduzindo modelos e padrões econômicos e de vida propostos (GÉRARD, 2007; TEHINDRAZARIVELO, 2009; ROSA, 2016). Esses grupos e comunidades sofrem discriminação em várias esferas importantes como nos países industrialmente mais desenvolvidos, escolas, trabalho e ascensão social.

\section{CONSIDERAÇÕES FINAIS}

Da predominância do pensamento eurocêntrico na sua estruturação ocidentalizada e na sua atividade teórica da perspectiva de dominância, a economia organizada pela matriz informação-conhecimento-tecnologia é vista como uma saída do subdesenvolvimento para países que ainda não entraram em um processo de emergência. No entanto, no Haiti, muitas condições devem ser atendidas para alcançar esse objetivo. Elas se relacionam, em particular, com o grau de desenvolvimento institucional, com a qualidade do ambiente técnico e cultural, apesar de depender em grande parte do nível de desenvolvimento econômico.

Consequentemente, o desejo de institucionalização e normalização do capitalismo informacional no país, através da natureza de sociedade da informação e do conhecimento, não pode se esquivar das condições materiais de sua produção. De fato, a ideia da economia da informação e do conhecimento parece muito incerta, na medida em que procede de uma redução do trabalho e da produção para a única dimensão cognitiva ou informacional, desconsiderando, assim, a sua dimensão material. Extensão das diversas mutações da economia informacional, a sociedade da informação e do conhecimento se inscreve como parte da preocupação de uma "superação" de ideologias marcadas pela expansão do capitalismo dos países e comunidades do centro e se reduz a um determinismo tecnológico abstraindo a dimensão da história.

Sob as lentes da economia política, a real análise dos mecanismos econômicos de configuração da sociedade de informação e de conhecimento no Haiti se deve empreender na busca das significações imaginárias entre o país e a economia globalizada. As implicações desses imaginários abrangem o entendimento de que o desenvolvimento nacional está enraizado na hipótese central que sustenta a ideia de que o subdesenvolvimento econômico do país, como forma social-história, seria demarcado por condicionantes sócio-históricos decorrentes das suas relações ao "outro-externo" na sociedade globalizada e ao "outro-interno" no país. 
Deste fundamento, a abordagem imanente do enquadramento da sociedade da informação e do conhecimento e suas dimensões econômicas no país, considerada como sistema dinâmico globalizado de significados estabelecidos, requer a distinção de duas esferas de entendimento. A primeira esfera de compreensão de significado é o da apreensão imediata da sociedade haitiana como sociedade subdesenvolvida (sentido imediatista e funcionalista da sociedade da informação e do conhecimento). Isto é o nível de apreensão da sociedade haitiana subdesenvolvida como descrito nos discursos sócio-históricos; uma sociedade configurada por múltiplas hierarquias, divisões imaginárias e materiais, dilacerada pelas desigualdades de acesso a recursos, exclusão da maioria dos esferas de poder e as incapacidades das instituições públicas e indivíduos sócio-históricos.

A segunda esfera se enquadra no significado histórico dessa realidade. É a esfera da análise do processo de configuração das categorias análiticas da sociedade haitiana subdesenvolvida, nas dinâmicas e processos de transformação dos constituintes capitalistas de organização econômica através da matriz composta pela informaçãoconhecimento-tecnologia, como um trabalho histórico-social. Neste estágio, entende que é fundamental a demarcação dos momentos do processo de configuração da sociedade haitiana subdesenvolvida na dinâmica da sociedade globalizada e a descoberta da lógica sócio-histórica subjacente às etapas de transformação do imaginário que constitui esse modelo de sociedade. De fato, a sociedade haitiana subdesenvolvida como sistema de significados institucionalizados é compreensível na dinâmica de alteração de ordem do significado da sociedade expressada em ordem colonial, ordem internacional e ordem mundial.

Nesse quadro político globalmente instituído, a realização do capitalismo informacional, no seu estágio de sociedade da informação e do conhecimento, em uma real transição econômica no país, depende efetivamente das condições e possibilidades de sua alteridade tanto política, cultural como econômica nesta ordem mundial. Portanto, a cristalização funcional e correlacional entre estas ordens: "colonial, internacional e mundial" que orienta os modelos de desenvolvimento e emancipação socioeconômica gera obstáculos para os avanços específicos nos países periféricos desde uma perspectiva de dignidade e autoridade da filosofia do Estado nacional que até então estrutura a governança econômica em um cenário de cooperação internacional de desconfiança.

No Haiti, os ideias de progressos sejam econômicos, políticos e culturais emanados no interior do capitalismo informacional estão enraizados nos ideias iluministas, como esfera de demarcação das relações de poderes, que se resultam na apropriação da natureza de sociedade por grupos privilegiados, absorção de culturas não científicas e não ocidentais - reproduzindo diversas formas de violências, dos espectros internacionais ao espectro nacional, em formas proporcionais de desigualdade, pobreza e opressão em relação ao grau de normalização referencial das comunidades.

Artigo recebido em 02/02/2020 e aprovado em 27/04/2020.

\section{REFERÊNCIAS}

ALLIANCE FOR FINANCIAL INCLUSION. Mesurer I'inclusion financière: ensemble des indicateurs de base d'inclusion financière. Note directrice, no 4, élaboré par le FIDWG, Bangkok, 2013. 
AGUADERO, Francisco. La sociedad de la información. Madrid: Acento, 1997.

AMNISTÍA INTERNACIONAL. ¿Dónde vamos a vivir? Migración y apatridia en la República Dominicana y Haití. Londres, 2016.

BASSO, Pietro. Modern times, acient hours: working lives in the twenty-first century. London; New York: Verso, 2005.

BATALOVA, Jeanne; SCHULZ, Jennifer. Haitian immigrants in the United States. Migration Policy Institute. Migration Information source. New York, 2017.

BAZIN, Marc. Sortir de l'Impasse. Manuscrit, Port-au-Prince, 2006.

BELL, Daniel. Vers la société post-industrielle, Robert Laffont, Paris, 1978.

BERGER, Laurent. Capitalisme et mondialisation: de l'autonomie des trajectoires locales à l'interdépendance systémique globale. Paris: La Découverte, 2009.

BIDEGAIN, Gabriel. Reconstruction et fuite de cerveaux. Fonds des Nations Unies pour la Population (UNFPA). Port-au-Prince, 2012.

BOST, François. Les zones franches, interfaces de la mondialisation. Annales de géographie 2007/6, $n^{\circ} 658$, p. 563-585.

BRISSON-LAMAUTHE, Nathalie. Emploi et pauvreté en milieu urbain en Haití. Commission Economique pour l'Amérique Latine et les Caraïbes. LC/MEX/R.882, 2005.

BUREAU INTERNATIONAL DU TRAVAIL. Programme Pays pour le Travail décent en Haïti 2015-2020. Port-au-Prince, 2015.

BUZENOT, Laurence. Industrialisation, zone franche et développement socio-spatial dans les espaces insulaires: les cas des îles de la Caraïbe et de l'île Maurice. HAL: Archives ouvertes. France, 2013.

CASTELLS, Manuel. A sociedade em rede. São Paulo: Paz e Terra, 2011.

CHARLES, Emmanuel; ST-FLEUR, Schmied. Amélioration des données sur les migrations en Haïti: Évaluation et recommandations. Observatoire ACP sur les Migrations. Port-au-Prince, 2014.

CLEMENS, Michael A. Does Development reduce migration? Discussion paper series. Bonn: Institute for the Study of Labor (IZA), 2014.

COLLIER, Paul et al. Globalization, growth, and poverty. London: Oxford University Press, 2002.

DALEMBERT, Louis-Philippe. Haïti, la dette originelle. Grand angle: Libération, 2010.

DE WENDEN, Catherine Wihtol. Les migrants pris au piège d'un monde injuste. Un monde d'inégalités. Cairn.info. France, 2017.

DESPINAS, Jean-Yves. La pauvreté en Haïti: contextes historique et politiques d'ajustement structurel. Port-au-Prince: La Rebelle, 2008.

DEPARTEMENT FEDERAL DES AFFAIRES ETRANGERES. Stratégie de coopération suisse en Haïti: 2018-2021. Port-au-Prince, 2017.

DUPUY, Alex. Haiti in the world Economy: class, race and underdevelopment since 1700. New York: Routledge, 2018. 
ÉCOLE DE POLITIQUE APPLIQUÉE. Faculté des lettres et Sciences Humaines. Perspective monde: outil pédagogique des grandes tendances mondiales depuis 1945. Université de Sherbrooke, Québec, Canada, 2020.

EMILE, Etzer. S. Haiti a choisi de devenir pauvre: Les vingt raisons qui le prouvent. Port-au-Prince, 2017.

FASS, Simon, M. Political economy in Haïti: the drama of survival, Transaction-Books, New Brunswick, Canada, 1990.

GAGNON, Jacinthe. L'immigration, dernier rempart de la souveraineté de l'État? Cahier de recherche. Laboratoire d'étude sur les politiques publiques et la mondialisation. n. 3, vol. III, Québec, 2010.

GAGNON, Jacinthe. Analyse des impacts de la mondialisation sur l'économie au Québec. Laboratoire d'étude sur les politiques publiques et la mondialisation. Rapport 5, Limmigration, corollaire du développement économique?, Canada, 2008.

GALLOUJ, F. Cycles économiques et innovations de service: à la lumière de la pensée schumpéterienne. Revue française d'économie. n. 9, vol. 4, p.169-213, 1994.

GRAMSCI, Antonio. Maquiavel, a política e o Estado moderno. Trad. Luis Mário Gazzaneo. Rio de Janeiro: Civilização Brasileira, 1968.

Hedra, 2008.

Americanismo e fordismo. Trad. Gabriel Bogossian. São Paulo:

GÉRARD, Noiriel. Immigration, antisémitisme et racisme en France (XIXe-XXe siècle): discours publics, humiliations privées. Paris: Hachette, 2007.

GOUVERNEMENT DE LA RÉPUBLIQUE D'HAÏTI. Plan stratégique de développement d'Haïti: Pays émergent en 2030. Tome I: Les grands chantiers pour le relèvement et le développement d'Haïti. Document de consultation publique. Port-au-Prince, 2012.

GREENIDGE, Chanzo. Migration Policy of Haiti: 2015-2030. Document de politique. Port-au-Prince, 2015.

HECTOR, Michel. Réflexion sur les particularités de la revolution haitienne. Bulletin de la société d'histoire de la Guadeloupe, Barbade, n. spécial, 2006.

HUWS, Ursula. Mundo material: o mito da economia imaterial. Revista Mediações, Londrina, v. 16, n. 1, p. 24-54, 2011.

HARRIBEY, Jean-Marie, La richesse, la valeur et l'inestimable: fondements d'une critique socio-écologique de l'économie capitaliste. Paris: Les Liens qui libèrent, 2013.

INTERNATIONAL ORGANIZATION FOR MIGRATION. Migration and the 2030 Agenda. A Guide for Practitioners. Geneva, 2018.

INTERNATIONAL CRISIS GROUP. Construire la paix en Haïti: inclure les Haïtiens de l'étranger. International Crisis Group.Rapport Amérique latine/Caraïbes $n^{\circ} 24.14$ décembre 2007.

JEAN, Fritz A. Haïti, la fin d'une histoire économique. Les Presses de l'Université Notre-Dame. Port-au-Prince, 2015

JEAN, Fritz A. Haïti, une économie de violence. Presses Notre-Dame, Port-au-Prince, 2018.

JOSÉ, Magliano María. Interseccionalidad y migraciones: potencialidades y desafíos. Estudos Feministas, vol. 23 n. 3, 2015. 
KAHANEC, Martin; ZIMMERMANN, Klaus F. International Migration, Ethnicity and Economic Inequality. Discussion paper series. Bonn: Institute for the Study of Labor (IZA), 2008.

LABOUSSIERE, Eddy Nicolas. Crédibilité et efficacité de la politique monátaire emphase sur Haïti. Thèse. École Doctorale de I'Université Antilles-Guyane. Guyanne, 2013.

LAROSE. Sandy R. République d'Haïti et République Dominicaine: une nouvelle forme de relation (Nord/Sud) entre deux pays du Sud. Presses Quisqueya; Port-au-Prince, 2016.

LAZZARATO, Maurizio; NEGRI, Antonio. Trabalho imaterial. Rio de Janeiro: DP\&A, 2001.

MADEIRA DA SILVA, Camila Antunes. Xenofobia direcionada aos imigrantes haitianos na República Dominicana: motivações e implicações. In: II SIMPÓSIO INTERNACIONAL PENSAR E REPENSAR A AMÉRICA LATINA, 2016, São Paulo. Anais [...], São Paulo, 2016.

MINISTÈRE DE L'ECONOMIE ET DES FINANCES. Bulletin statistique de la dette publique: exercice 2016-2017. Bulletin no 003; 3ème trimestre. DGTCP: Direction Général du Trésor et de la Comptabilité publique, Juin 2017.

MINISTÈRE DE L'ECONOMIE ET DES FINANCES. Bulletin statistique de la dette publique: exercice 2017-2018. Bulletin no 006; 2ème Trimestre. DGTCP: Direction Général du Trésor et de la Comptabilité publique, Mars 2018.

MINISTÈRE DES AFFAIRES SOCIALES ET DU TRAVAIL. Évaluation des besoins post cyclone Mathieu: Secteur emploi et Moyen de Subsistance. ECVMAS 2012. Port-auPrince, 2016.

MÉSZÁROS, Istvan. Para além do capital, rumo a uma teoria da transição. São Paulo: Boitempo, 2011.

METZNER, Tobías. La migración haitiana hacia Brasil: Estudio en el país de origen. Cuadernos migratorios, n. 6. La migración haitiana hacia Brasil: Características, oportunidades y desafíos. Oficina regional para américa del sur. Argentina, 2014.

MOULIER-BOUTANG, Yann. Cognitive capitalism. London: Polity Press, 2011.

NATIONS UNIES. Construire des secteurs financiers accessibles à tous. New York, Nations Unies, 2006.

NIETO, Carlos. Migración haitiana a Brasil. Redes migratorias y espacio social transnacional. Informe de Investigación Programa de Estudios sobre la pobreza, CLACSO, 2014.

OGÉCIME, Mardochée; MOURA, Maria Aparecida. Sociedade da informação e do conhecimento: condições e possibilidades de desenvolvimento na periferia. In: IV REDE FRANCO-BRASILEIRA DE MEDIAÇÃO DA INFORMAÇÃO, 2019, Belo Horizonte. Anais [...], Belo Horizonte, 2019a.

OGÉCIME, Mardochée; MOURA, Maria Aparecida. As aporias da economia da economia política da informação e do conhecimento no interior do capitalismo informacional. In: XX ENCONTRO NACIONAL DE PESQUISA EM CIÊNCIA DA INFORMAÇÃO, 2019, Florianópolis. Anais [...], Florianópolis, $2019 \mathrm{~b}$.

ORGANIZACIÓN INTERNACIONAL PARA LAS MIGRACIONES. Diagnóstico regional sobre migración haitiana. Impresión: Irap. Argentina, 2017. 
PAIK, Naomi A. Carceral Quarantine at Guantánamo: Legacies of U.S. Imprisonment of Haitian Refugees. Radical History Review. Washington, 2013.

PAUL, Bénédique; DAMEUS, Alix; GARRABE, Michel. Le processus de tertiarisation de I'économie haïtienne. Études caribéennes. Diasporas protéiformes. 2010.

PEREIRA, Margarida. Governança territorial multinível: fratura(s) entre teoria e prática(s). DRd - Desenvolvimento Regional em debate. v. 4, n. 2, p. 4-20, jul./dez. 2014.

PLATEFORME HAÏTIENNE DE PLAIDOYER POUR UN DÉVELOPPEMENT ALTERNATIF. Crise alimentaire et les défis de la relance agricole en Haïti: Quelles réponses aujourd'hui?. Programme de Plaidoyer pour une Intégration Économique Alternative (IEA). Port-au-Prince, 2008.

PORRAS, Laila. Croissance, inégalités et pauvreté au sein des pays émergents: le cas des BRICS. 18 | 2e semestre / Autumn 2015 : Contestations monétaires. Une économie politique de la monnaie. Revue de la régulation: Capitalisme, institutions, pouvoirs. Paris, 2015.

PRADO, Eleutério Fernando da Silva. Pós-grande indústria e neoliberalismo, Revista de economia política, v. 25, n. 1, p. 11-27, jan-mar. $2005 a$.

PRADO, Eleutério Fernando da Silva. Uma nova fase do capitalismo ou um novo modo de produção capitalista? Revista Outubro, v. 13, n.1, p-47-57, 2005 b.

RIDORÉ, Géraldine. Étude sur le développement financier et la croissance économique en Haïti sur la période 1986-2010, mémoire de licence (sciences économiques), Université d'État d'Haïti, 67 p. Port-au-Prince, 2011.

ROSA, Renata de Melo. A construção da desigualdade no Haiti? Experiências históricas e situações atuais. Brasília, 2016.

SANTOS, E. A. Crédito à morte: A decomposição do capitalismo e suas críticas, de Anselm Jappe. Plural, v. 20, n. 2, p 219-222, 2013.

TEHINDRAZARIVELO, Djacoba Liva. Le racisme à l'égard des migrants en Europe. Collection: Migration. Publishing Editions: Conseil de l'Europe. Paris, 2009.

TEIXEIRA, Rodrigo Alves; ROTTA, Tomás Nielsen. Valueless knowledge-commodities and financialization: Productive and financial dimensions of capital automatization. Review of Radical Political Economics. v. 44, n. 4, 2012.

THOMAS, Madiou. Histoire d'Haïti: tome III. Henri Deschamps. PAP, Haiti, 1989.

TOURAINE, Alain. La société post-industrielle: naissance d'une société. DenoëlGonthier, Paris, 1969.

UNITED NATIONS. Transforming our world: The 2030 agenda for sustainable development. A/RES/70/1. New York, 2016.

UNITED NATIONS. International Migration Stock: The 2015 Revision (banco de Dados).

VENTURA, Jaume; BRONER, Fernando. Rethinking the effects of financial globalization. The Quarterly Journal of Economics, Volume 131, Issue 3, August 2016, Pages 1497-1542.

VINCENT, Miloody; CHERY, Jean Claude. Présentation synoptique sur la situation des TIC en Haïti. Atelier mondial sur les indicateurs d'accès communautaire aux TIC, 16 19 novembre, Projet HAI/98/003; Mexico, 2003. 
WORLD SUMMIT ON THE INFORMATION SOCIETY. Declaração de Princípios: construir a sociedade da informação: um desafio global no novo milênio. Tunis, 2005.

WORLD TRADE ORGANIZATION. International trade statistics 2014. Geneva, 2014.

ZANUSO, Claire; ROUBAUD François; TORELLI, Constance. Le marchée du travail en Haïti après le séisme: quelle place pour les jeunes. Presses de sciences Po. Autrepart. n. 71 - vol 3. 2014. 